\title{
Creating Art by 3D Pen
}

\author{
Qiaohong Wei ${ }^{1 *}$ and Seeram Ramakrishna ${ }^{2}$ \\ ${ }^{1}$ Founder of Vicky3D Art, China \\ ${ }^{2}$ Department of Mechanical Engineering, National University of Singapore, Singapore
}

Submission: April 19, 2020; Published: June 26, 2020

*Corresponding author: Qiaohong Wei (Vicky Wei), Founder of Vicky3D Art, China

\begin{abstract} aimed at introducing

a) How 3D pen works?

b) Examples drawn by 3D pen.

c) Variety of materials and color choices.

d) Types of 3D pens in the market and

e) Future possibilities.
\end{abstract}

3D printing technology is a new rapid prototyping technology, but 3D pen is a pen with 3D printing function, it's extrudes heated or warm molten plastic from the pen's nozzle. You don't need any software, there are no files to transfer. whatever you imagine, you can draw. It goes from your brain, to your hand. It can cultivate students' innovative thinking and problem-solving ability in maker education. Despite the many advantages of 3D pens in artistic creation and education, the popularity of 3D pens is so low that many people do not even know the technology or how to use it. When entering "3D pen" or "application of 3D pen" for paper retrieval, the relevant literature can hardly be found. This article is

Keywords: 3D pen; Application of 3D printing pen; 3D printing; Maker education; Childhood education; Innovative thinking; Art; DIY; Threedimensional painting; Cultural transmission

\section{Review}

For millennia, people around the world are enticed with beautiful, enticing and intriguing drawings, watercolor paintings and oil paintings drawn on different media. Imagine the impressions on people if they are three dimensional instead of mere two dimensional! With the emergence of three-dimensional printing pen or 3D pen, it is now feasible to draw a variety of three-dimensional patterns in the air, like a magic pen. This article is aimed at introducing
a) How $3 \mathrm{D}$ pen works?
b) Examples drawn by 3D pen.
c) Variety of materials and color choices.
d) Types of 3D pens in the market and
e) Future possibilities.

\section{History and Introduction}

The following schematic, Figure 1 outlines timeline of major technological/scientific milestones in western artover thousands of years, from pre-classical art to classical art, medieval art, European
Renaissance art, baroque and rococo art, $19^{\text {th }}$ century western art, to western modernist art. Chinese art has a long history. Unlike Europe, where art styles are always changing, Chinese art has maintained a surprising continuity over the centuries. The works of the Ming dynasty can also see the influence of the tang dynasty. A painting from the Qing dynasty is very similar to one from the song dynasty. One reason is China's reverence for tradition. Since the $16^{\text {th }}$ century, Chinese arts and crafts, especially porcelain, were exported to Europe in large quantities, which also had an impact on European art. After the republic of China, traditional Chinese art developed with the rapid changes of the times. Chinese painters began to study in the west and have direct contact with European paintings, such as Xu Beihong and others. The establishment of new painting school also promotes the westernization of Chinese painting [1]. The evolution of Indian art style is not only governed by the discipline of formal beauty, but also related to the evolution of Indian religion and philosophy. The ancient art scene of India: bright colors, colorful and exaggerated shapes, and the belief in the afterlife and the past. While highlighting the strong national characteristics, it has also absorbed many artistic factors from Europe and west Asia. 


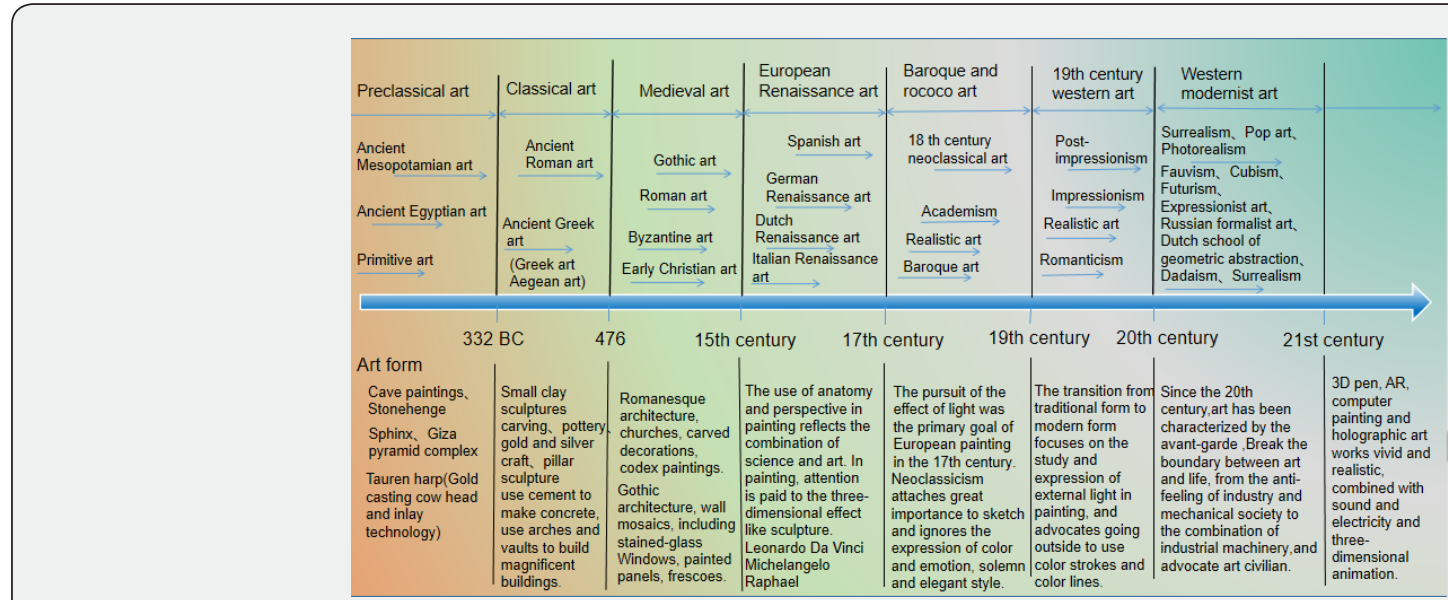

Figure 1: History of Western Art.

Technological/scientific and art are mutually reinforcing. In the primitive times, only stone chisel technology, red earth as the material, so the rock painting murals; The Neolithic pottery technology, the color pottery above can leave beautiful geometric patterns and animal-shaped patterns. The invention of smelting technology, people cast all kinds of copper and iron, with a metal texture chisel to carve David and other masterpieces. Therefore, smelting technology plays a crucial role in the art of sculpture. The invention of oil paints, as well as the use of perspective, golden section, optics, color, anatomy, black box and other scientific principles and techniques in painting to make painting works closer to the real things. Da Vinci left the Mona Lisa's eternal smile. With the development of photography technology, nature can be vividly represented. With the gradual improvement of computer technology and functions, painting has developed from the original sketching to computer painting and holographic art works vivid and realistic, combined with sound and electricity and three-dimensional animation [2].

\section{How 3D Pen works?}

First, connect the power supply of the 3D pen, the power indicator light will be on, click the feed button, the heating lamp will turn red, the 3D pen will start pre-heating, about 50 seconds of pre-heating completed, the indicator light from red to green (Figure 2). Then press the feed button and add the filament into the feed port [3]. The mechanical device in the pen will send the filament to the heating nozzle to start using. When it does not have any operation within 90 seconds, the system will automatically enter the sleep state, which can effectively avoid wasting energy without any operation for a long time. When the feed button is clicked again, the 3D pen can be awakened. When finished using, press the return button to exit the remaining wire. The 3D pen supports portable power supply, making it safe and convenient. 3D pens from different manufacturers may vary slightly, but the principle is the same (Table 1). Simple 3D pen techniques and skills. Drawing with a 3D pen is like drawing and writing with crayons, pencils and pens you just need to gain control and confidence [4]. It is useful to learn basic techniques and practice on simple 2D templates first. Practice will give you good control. Once you have mastered the art of drawing with a 3D pen, you can draw any three-dimensional pattern or model. The 3D pen allows people to visualize their thoughts and shape your ideas into real shapes.

Table 1: A list of various manufacturers of 3D Pens and their Websites.

\begin{tabular}{|c|c|c|}
\hline Serial Number & Manufacturers of 3D Pens & Websites \\
\hline 1 & 3Doodler & https://learn.the3doodler.com \\
\hline 2 & Polaroid Play 3D Pen & https://www.3dplaypen.com/ \\
\hline 3 & Nanjing Qianwei Intelligent Technology Co., Ltd & http://www.quncreate.cn \\
\hline 4 & Zhuhai Sunlu Industrial Co., Ltd. & http://www.com \\
\hline 5 & Wu Yi Sting 3D Technology Co., Ltd & http://zh_tw.ysfilament.com \\
\hline 6 & Guangzhou Yousu 3DTechnology Co., Ltd & \\
\hline
\end{tabular}




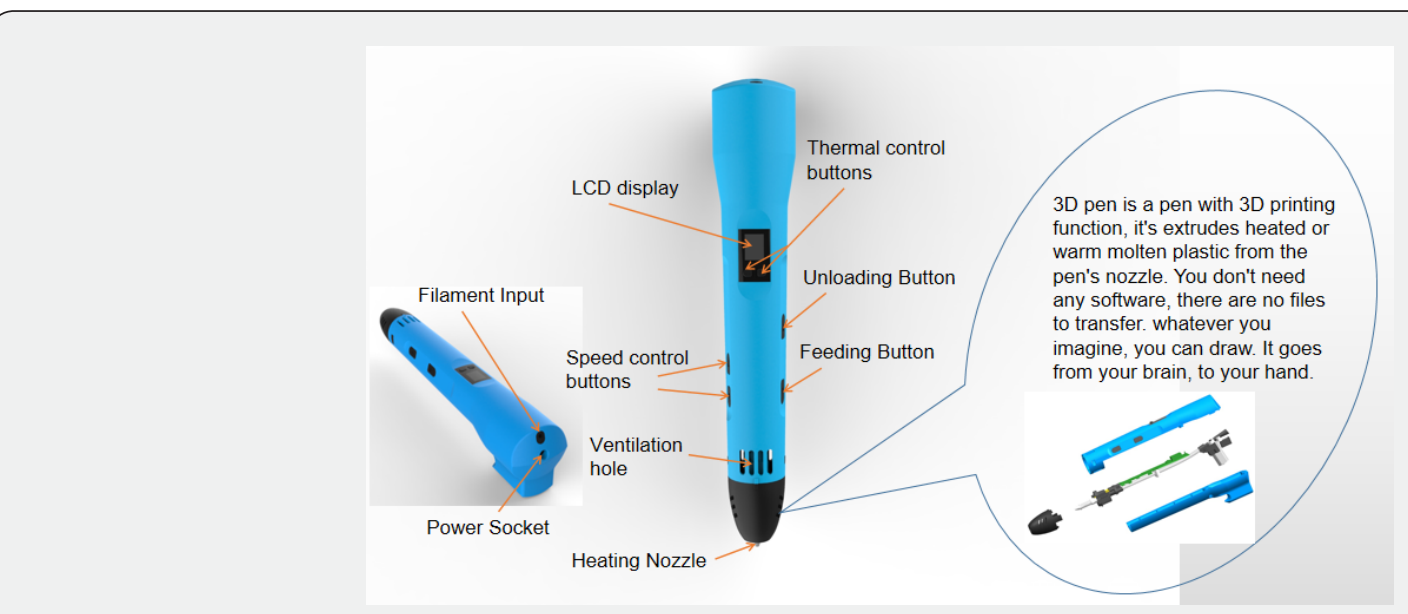

Figure 2: The Scientific Mechanism/Principle of operation of 3D Pen.

\section{Examples Drawn by 3D Pen}

The 3D pen is like any other tool and skills, it takes a little patience and practice to learn how to use it and gain proficiency. It takes time and practice to draw and model with hot molten plastic.

Design awareness and capability are life skills. To cultivate the creative ability of primary and secondary school students, 3D pens are brought into the classroom in an easy and interesting way, enabling students to cultivate and exercise innovative thinking and creativity through the latest technological tools (Figure 3). For example, in the campus science and technology innovation competition, if the appearance of the entries needs to be modified or some spare parts are needed, then the 3D pen can quickly solve these problems [5]. Schools encourage the exploration of new modes of education. As a new tool used in teaching, 3D pen can turn learning into a process of innovation and creation, cultivate students' creative thinking, creativity and teamwork ability, and pay attention to the connection between learning and the real world, instead of just the test results of test papers (Figure 4). 3D pens are suitable for people of all ages. Whether they are children, adults or the elderly, anyone can draw with a 3D pen. Fire your imagination, activate your design capability, Enjoy the fun of creating (Figure 5). You can use a 3D pen to make a gift for your family and friends. It will be a special gift because you have made it yourself. You can also use a 3D pen to complete a beautiful painting or make any three-dimensional object to use as an interior decoration. It's a great way to relieve stress for office workers [6].

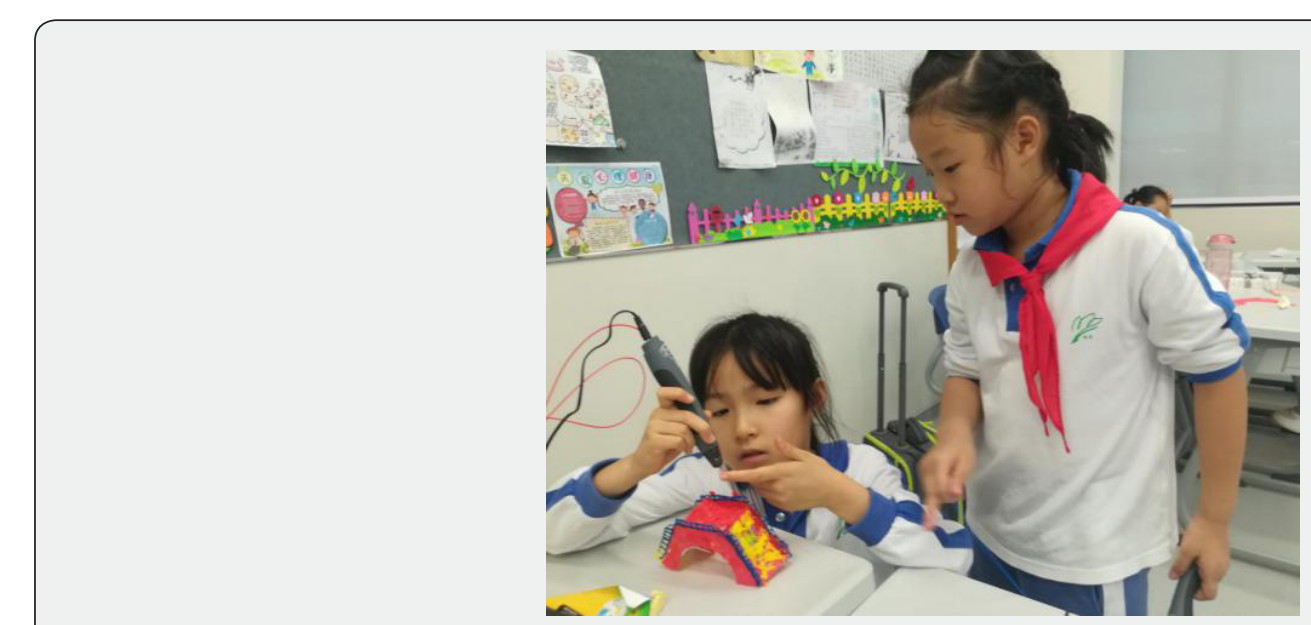

Figure 3: The Students are using 3D pens to make works.

The 3D pen can be combined with comprehensive materials to create and solve problems in real life. The 3D pen is a practical tool for DIY enthusiasts. For example, when we want to do a unique small electric fan, need to prepare electronic components for electric fans, motor, blade, batteries, electric wire, switch, and then use 3D pen draw the lid of the electric fan, fixed bracket, draw some beautiful adornment, a unique fan was finished, it can be used as works of art and can be used as a practical article for 
daily use (Figure 6). It is a good drawing tool for architects and product designers. The covid-19 epidemic of 2020 has emerged and spread so fast that we are all facing a severe test. Due to the outbreak, people have to wear masks to go out and work. However, many masks are produced without considering the need for the tightness and length of the ear strap for a long time. Moreover, the ear strap of the mask needs to be hung on the ear, which can be very painful due to the pressure of the rope on the ear root for a long time. In order to solve the problem of mask wearing, you can use 3D printing pen to design a beautiful and practical "mask adjusting band". When wearing a mask, the ropes on both sides of the mask can be stuck on the mask adjusting band to free the ears from being squeezed. Wearing masks can also become fashionable (Figure 7). 3D pen painting is another expression form of 21st century painting, which is to inherit, integrate and improve ancient and modern Chinese and foreign things and historical culture. It can make the picture more three-dimensional, colorful, with a very good visual effect, and not easily affected by moisture. 3D pen painting expands the space for artistic creation, allowing artistic works to be presented in various forms (Figures $8 \& 9$ ).

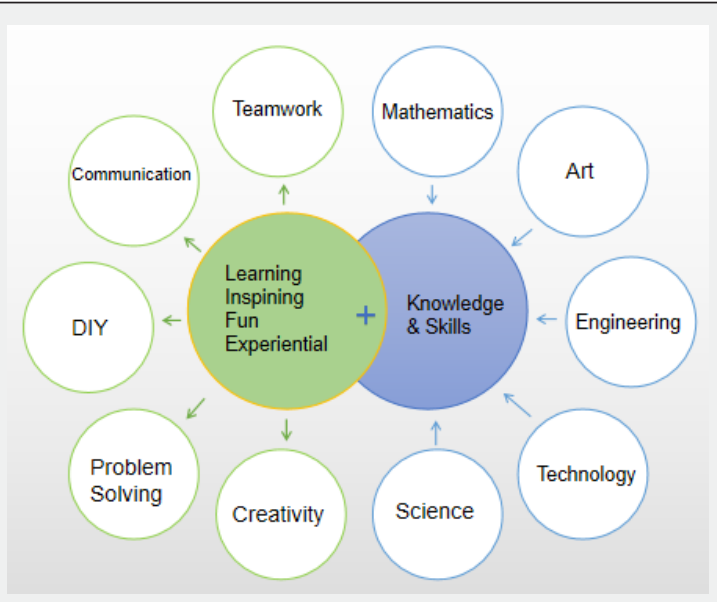

Figure 4: A Schematic of Improvements in the Learning Abilities and Interests of Students.

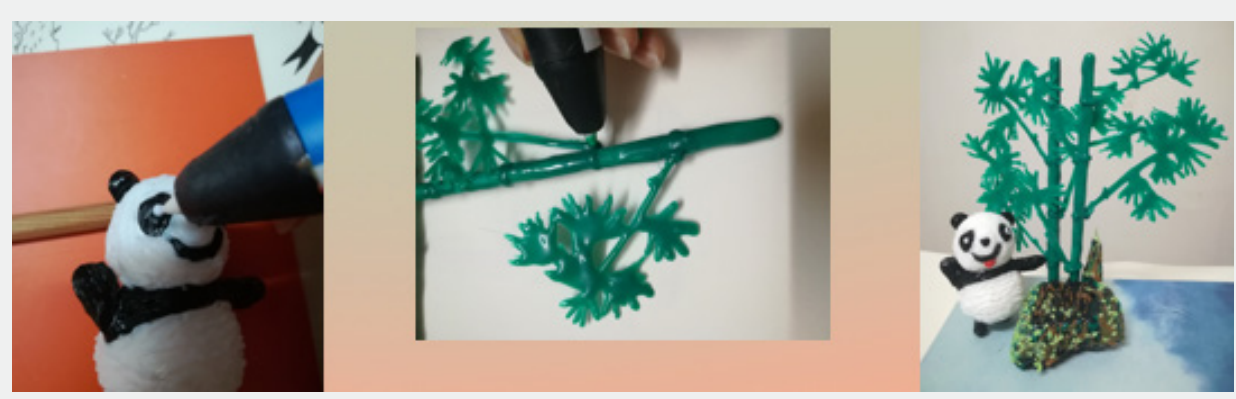

Figure 5: This Picture is the Panda and Bamboo Made by the 3D Pen.

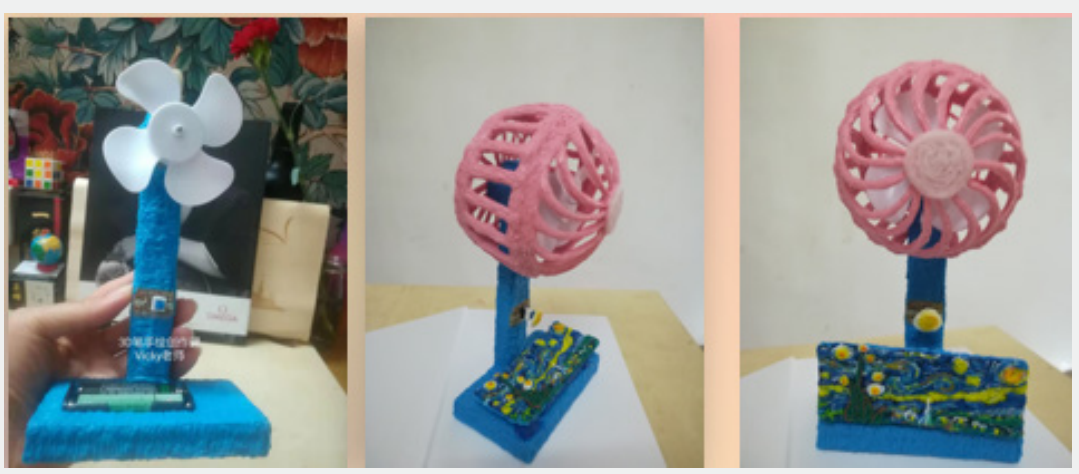

Figure 6: This is a Practical Little Fan Made by 3D pen. 


\section{Current Trends in Fashion Technology \& Textile Engineering}

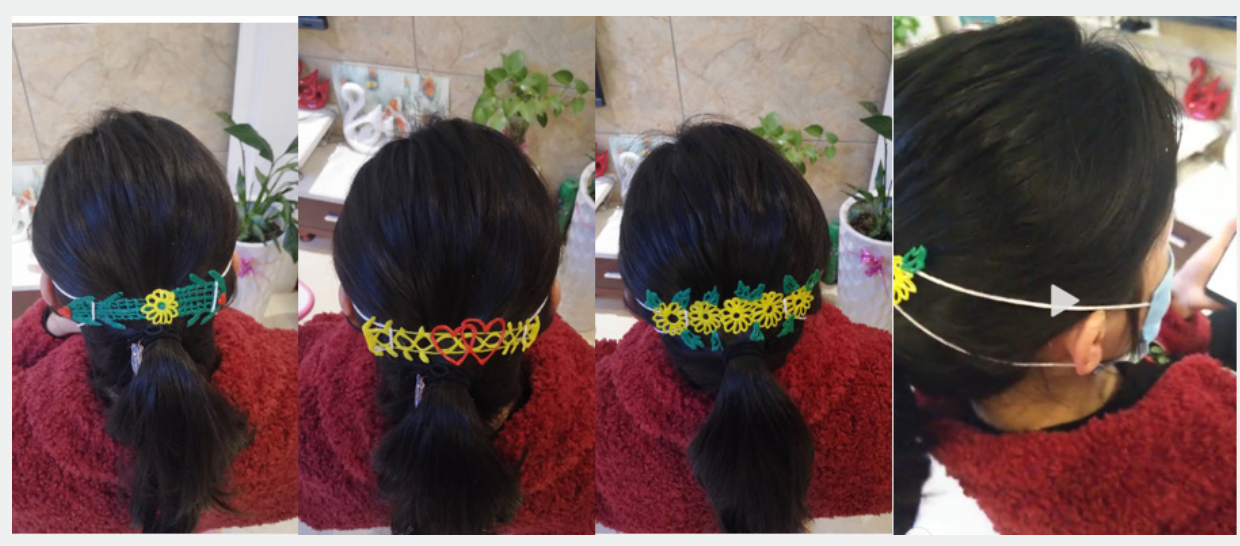

Figure 7: Mask Adjustment Tape Made with 3D Pen allows the Ears to be Free and not Squeezed.

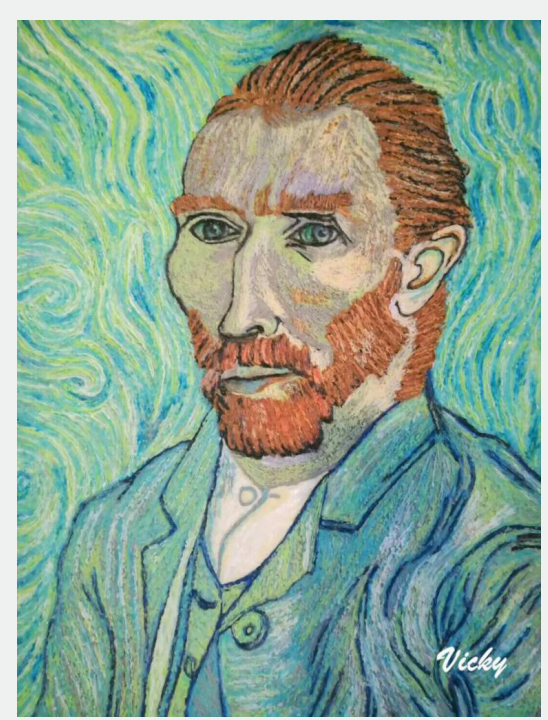

Figure 8: 3D pen Three-Dimensional Oil Painting Artistic Effect.

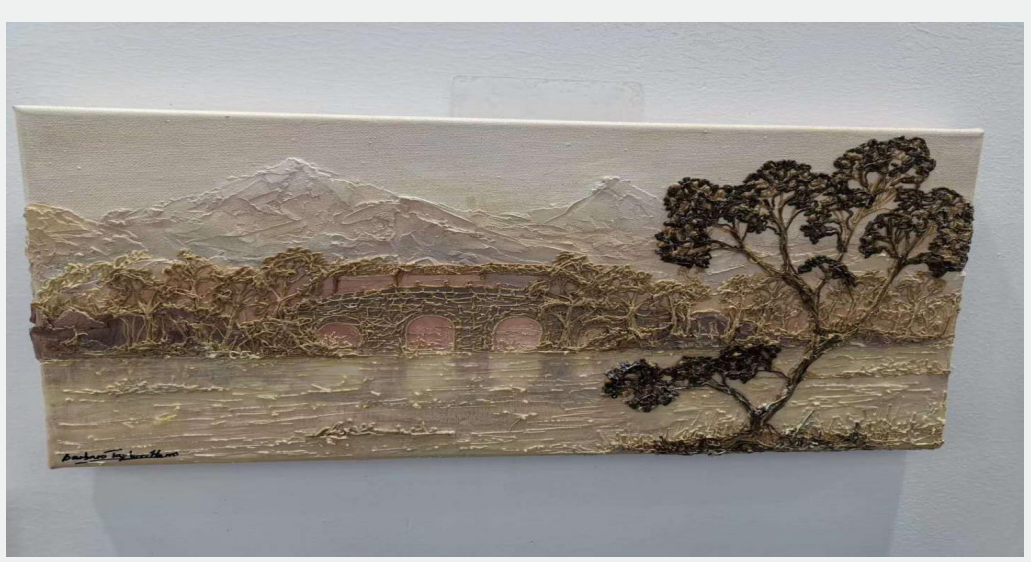

Figure 9: The Artistic Effect of 3D Pen+Oil Paint. 


\section{Variety of Materials and Color Choices}

The consumables (Table 2) used for the 3D pen are ABS, PLA and PCL, monofilament $(\varnothing=1.75 \mathrm{~mm})$. ABS is an engineering material with a melting temperature of $217-237^{\circ} \mathrm{C}$, and it has an unpleasant smell during use, so not many people use it now. Polylactide (PLA) is a bio-based and renewable biodegradable material, which is made from materials extracted from renewable grain husk, straw and straw. After being used, it can be completely degraded by nature under specific conditions and eventually generate carbon dioxide and water without polluting the environment. The melting point of PLA is $155-185^{\circ} \mathrm{C}$. The molten PLA material is rapidly cooled and solidified in the air after coming out of the pen, forming hard lines, so that the three-dimensional model can be drawn directly in the air, which is very advantageous for making architectural models and three-dimensional structure models. Polycaprolactone (PCL) is a biodegradable material with many excellent characteristics, such as excellent low temperature plasticity, $58-70^{\circ} \mathrm{C}$ melting point, good toughness and seawater degradation (Figure 10). The color of materials is very rich, there are already dozens of colors available on the market. And the color and luster of the material that different manufacturer produces can be different, some material color is very pure, some material color can be met light, people can choose different material color according to need. According to the experience of two different colors of materials can also be mixed like a pigment, so that your works will be very rich in color [7].

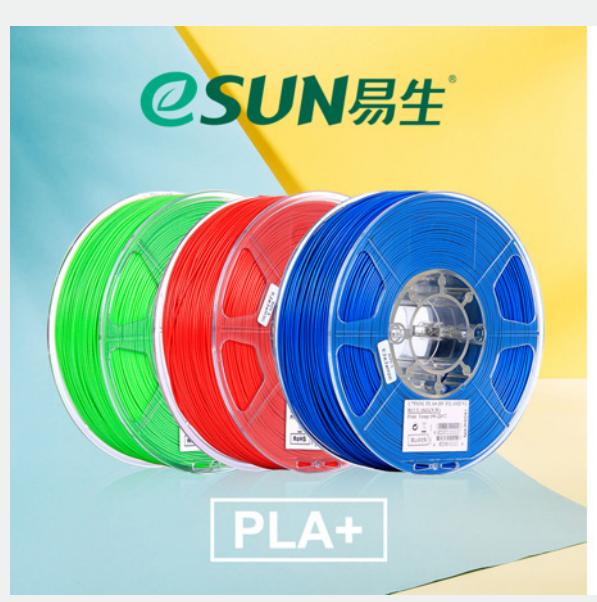

\section{eSUN易生}

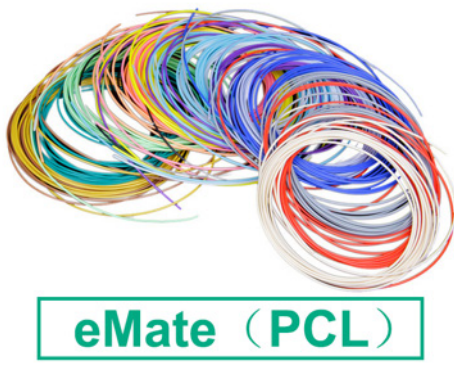

Figure 10: This is the Photo of PLA and PCL Materials Provided by Shenzhen Esun Industrial Co. Ltd.

Table 2: This Table is about the Color, Melting Point Temperature and Degradation of PLA, PCL and ABS filament.

\begin{tabular}{|c|c|c|c|c|}
\hline Materials & Melting Temperature & Ranges of Color Grades & Shades Available & Biodegradable Material \\
\hline PLA & $155-185^{\circ} \mathrm{C}$ & $\begin{array}{l}\text { More than } 30 \text { colors (Red, orange, } \\
\text { yellow, green, blue, purple, black, } \\
\text { white, brown, and so on) }\end{array}$ & Fast cooling, not easy to mix. & $\begin{array}{c}\text { Yes } \\
\text { (It's made from materials extracted } \\
\text { from renewable grain husk, straw and } \\
\text { straw) }\end{array}$ \\
\hline PCL & $58-70^{\circ} \mathrm{C}$ & $\begin{array}{l}\text { More than } 20 \text { colors (Red, orange, } \\
\text { yellow, green, blue, purple, black, } \\
\text { white, brown, and so on) }\end{array}$ & $\begin{array}{l}\text { It cools slowly, can mix } \\
\text { colors, follow the principle of } \\
\text { three primary color mixing. }\end{array}$ & $\begin{array}{c}\text { Yes } \\
\text { (It's a biodegradable material with } \\
\text { many excellent characteristics, seawa- } \\
\text { ter degradation) }\end{array}$ \\
\hline ABS & $217-237^{\circ} \mathrm{C}$ & $\begin{array}{l}\text { More than } 20 \text { colors (Red, orange, } \\
\text { yellow, green, blue, purple, black, } \\
\text { white, brown, and so on) }\end{array}$ & Fast cooling, not easy to mix. & $\begin{array}{c}\text { No } \\
\text { (It's an engineering material) }\end{array}$ \\
\hline
\end{tabular}

Types of 3D Pens in the Market

a) The first $3 \mathrm{D}$ pens to appear on the filament is the high temperature 3D pen, its operating temperature is around 180- $240^{\circ} \mathrm{C}$. When using ABS filament, the working temperature of 3D pen needs to be heated to about $220^{\circ} \mathrm{C}$. In such a high temperature condition, users are easy to be scalded by the pen tip, so few people use this kind of high-temperature 3D pen now. When using 
PLA filament, the working temperature of the pen is around $180^{\circ} \mathrm{C}$. Because of the good stereoscopic plastic effect and the relatively affordable price of the material, the sales volume of this 3D pen is very good.

b) It is known that users of $3 \mathrm{D}$ pens tend to be younger, especially among primary and secondary school students. In order to consider the safety of pens used by children, the low temperature 3D pen is now on the market, and its printing temperature is around $60^{\circ} \mathrm{C}$, which avoids the risk of children being burned by pens in the process of use. It can also be charged with an automatic power supply, making it safer and more convenient. Its corresponding filament is PCL.

c) There are also 3D pens with accumulators on the market, which do not need to be connected to the power supply all the time in the process of use and can work continuously for about two hours. However, its disadvantage is that the pen body is very heavy, which increases the burden of people's hands when painting.

\section{Future Possibilities}

The popularity rate of 3D pens is not very high, and the users are mainly concentrated in the first and second tier cities. Many people in towns and townships have not even seen 3D pens. However, many makers' centers and schools now offer classes on creating 3D pens, and it is believed that more people will use 3D pens in the next few years. At the same time, the quality of 3D pen will be constantly optimized, the product will be more and more exquisite, and the safety and stability will be better and better. I believe that there will be more people like to use this new painting tool for artistic creation (Figure 11).

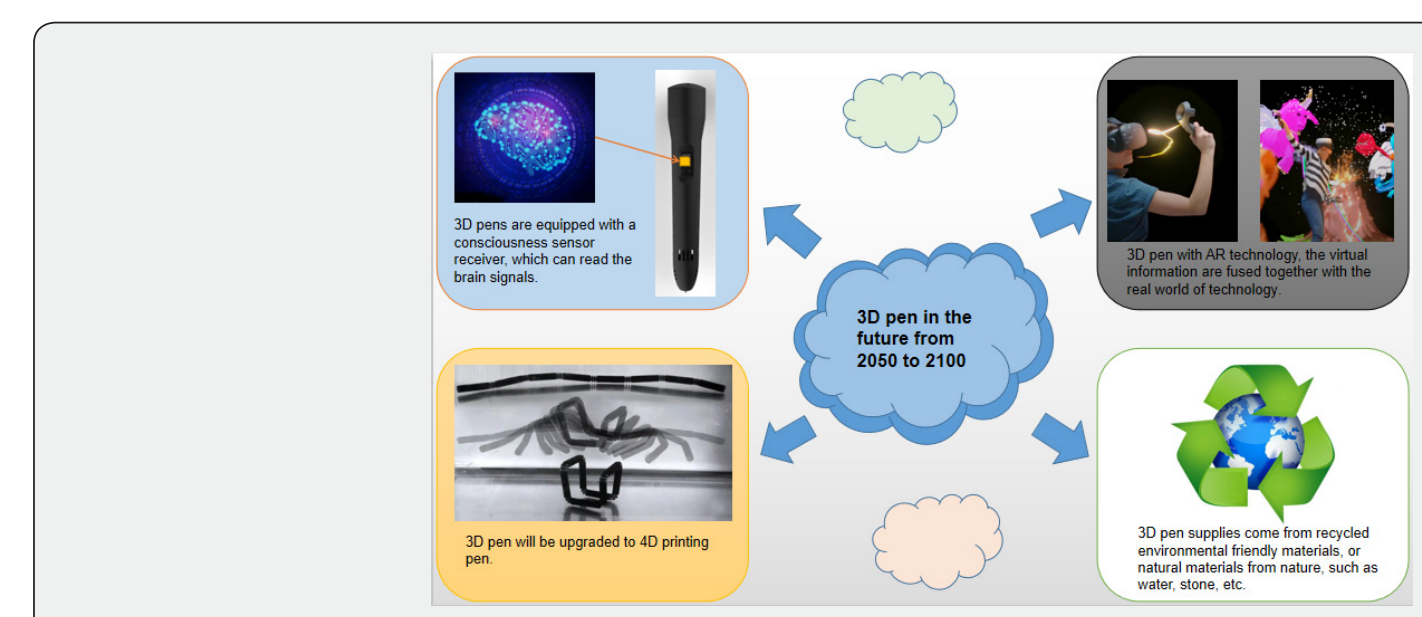

Figure 11: Imagine Future Possibilities with 3D pen in 2050 and 2100.

Technology and application of 3D pen in the future from 2050 to 2100 :

a) In the future, with the development of artificial intelligence, 3D pens are also equipped with intelligent technology. The pen is equipped with a consciousness sensor receiver, which can read the brain signals, read the things and pictures in our brain, and then the 3D pen will draw your thoughts automatically.

b) In the future, 3D pen will be upgraded to 4D printing pen. About "4D printing," compared to traditional 3D-printed parts, the additional dimension in the time domain allow for the components to undergo dramatic changes in shape when subjected to an external stimulus. stimuli that induce time-dependent behaviors are usually temperature changes or water exposure.

c) 3D pen with AR (Augmented Reality) technology, the virtual information are fused together with the real world of technology, the computer generated text, images, 3D simulation model, music, video and other virtual information, applied to the real world, at the same time to join 3D pen drawing entities part, two kinds of information complement each other, so as to realize the virtual and real world of perfect combination of artistic effect.

d) In a few decades' time, the 3D pen's consumables could come from recycled plastic materials that have been processed into biodegradable, environmentally friendly materials. The consumables of 3D pen can also come directly from the nature, such as drawing a river, people directly use water as raw material to print in the picture. Painting a mountain can directly use the stone as a material to print a picture of the stone and so on.

\section{Conclusion}

In the future 3D pen applications will bring great creativity to the art world.

\section{References}

1. Takagishi K, Umezu S (2017) Development of the Improving Process for the 3D Printed Structure. Scientific Reports 7: 1-10.

2. Erokhin KS, Gordeev KG, Ananikov VP (2019) Revealing interactions of layered polymeric materials at solid-liquid interface for building 
solvent compatibility charts for 3D printing applications. Scientific Reports 9: 1-14.

3. Eutionnat-Diffo PA, Guan YCJ, Cayla A, Campagne C, Zeng X, et al. (2019) Stress, strain and deformation of poly-lactic acid filament deposited onto polyethylene terephthalate woven fabric through 3D printing process. Scientific Reports 9: 1-18.

4. Sun YC, Wan Y, Nam R, Chu M, Naguib HE (2019) 4D-printed hybrids with localized shape memory Behaviour: Implementation in a functionally graded structure. Scientific Reports 9: 1-13.
5. Zastrow M (2020) 3D printing gets bigger, faster and stronger. Research advances are changing the image of a once-niche technology. News Feature 578: 20-24.

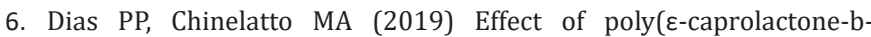
tetrahydrofuran) triblock copolymer concentration on morphological thermal and mechanical properties of immiscible PLA/PCL blends. J Renew 7(2): 129-138.

7. Ji-Geng Y (2014) The Interactive Development between Western Scientific Technology and Visual Art. Journal of Jincheng Institute of Technology 3 .

\section{Your next submission with Juniper Publishers will reach you the below assets}

- Quality Editorial service

- Swift Peer Review

- Reprints availability

- E-prints Service

- Manuscript Podcast for convenient understanding

- Global attainment for your research

- Manuscript accessibility in different formats

( Pdf, E-pub, Full Text, Audio)

- Unceasing customer service

Track the below URL for one-step submission https://juniperpublishers.com/online-submission.php 